\title{
Exploring the Role of Trust in Blockchain Adoption: An Inductive Approach
}

\author{
Martin Fleischmann \\ University of Bamberg \\ martin.fleischmann@uni-bamberg.de
}

\author{
Bjoern S. Ivens \\ University of Bamberg \\ bjoern.ivens@uni-bamberg.de
}

\begin{abstract}
While interest in blockchain technology and applications increases, research studying the role of trust as an element that leads potential users and consumers to adopt and accept the technology remains scarce. This study conducts acceptance research that expands beyond traditional acceptance models and explores the role of trust from the user/consumer perspective. It provides comprehensive insights from the user/consumer angle and a deeper understanding of the role of trust in blockchain adoption. Using an inductive research approach that builds theory from qualitative empirical data, this paper identifies trust as a critical benefit of blockchain technology and applications, encompassing both functional (economic and system-/ process-related) as well as emotional benefits (social and personal). As trust spans across functional and emotional benefit dimensions, this study suggests that trust is a key driver for user/consumer adoption of blockchain technology and applications.
\end{abstract}

\section{Introduction}

Blockchain technology attracts high attention among both academics and practitioners. In the realm of blockchain technology, trust is touted to be one of the central benefits offered by yet nascent blockchain applications [1] [2] [3] [4]. With regard to numerous other digital applications facilitated via the internet, researchers have identified trust as a key driver of technology adoption among users and consumers (UC), e.g. for e-commerce [5] [6] [7], online banking [8] [9] [10], or social media [11] [12] [13]. Consequently, it is also critical to deeply understand the relevance and importance of trust for acceptance of blockchain technology and applications. Therefore, this study explores the trust concept in the field of blockchain technology and applications to promote a differentiated in-depth understanding of its role for the UC, identifying pathways to build, change and leverage trust within the technology adoption process.

Extant research investigates the trust concept with regard to blockchain technology and applications primarily from a technology-focused information systems (IS) perspective that is closely related to engineering, programming, and computer science [3], evidencing that there is a need to study the topic more intensively from the UC angle [14] [15]. Likewise, many blockchain practitioners refer to trust as a key feature within the technical design of blockchain applications, though do not specify how exactly and in what way the trust created through blockchain technology and applications adds value to the UC [16] [17]. For researchers and practitioners alike, it is therefore essential to deeply explore the role of trust in blockchain technology and applications from the UC angle, in order to determine how trust can promote UC acceptance.

This research paper aims at adding to the existing body of literature by building an inductive, qualitative case study analysis around the following two research questions: Is trust a relevant benefit of blockchain technology and applications to the UC? And: Are there different facets of trust that UCs perceive as relevant and beneficial when it comes to blockchain technology and applications? Basically, this research pursues exploring the role of trust in blockchain technology and applications from the UC perspective, identifying the variety of meanings that trust represents to the UC. With these objectives in mind, the theoretical contribution [18] of present research is twofold: First, by approaching the blockchain topic from the UC perspective, this research takes a scarcely researched, alternate angle on the trust aspect in blockchain technology and applications, expanding and complementing extant, primarily technology-oriented research. Second, this research conducts an in-depth exploration of the role of trust in blockchain technology and applications, identifying different meanings and facets of the trust aspect from the UC perspective. Therefore, this research takes a UC-centric perspective 
on the benefit of trust, unveiling comprehensive insights that may be critical within the technology adoption process of blockchain applications. These insights may serve researchers for future blockchain-related work and guide practitioners in developing powerful blockchain applications that have a chance of UC acceptance, while application design is strongly linked to a differentiated understanding of trust that helps to build trust with UCs.

\section{Theoretical background}

Extant literature provides evidence that trust is a central aspect for technology adoption of digital applications. Therefore, researchers call for an investigation of trust in new, unexplored IS contexts [19] [20]. With regard to the nascent field of blockchain technology and applications, there is a strong need to explore the role of trust holistically from the perspective of the UC [14] [15]. This may provide crucial insights on how trust can be leveraged to promote UC acceptance of blockchain technology and applications.

\subsection{Trust}

Trust is a construct that has sparked discussions in the research community for decades, being approached from the most diverse angles in extant trust literature.

In essence, trust can be viewed as an enabler of social interactions as it represents the willingness of one party to have faith and rely on another party in situations that are characterized by social complexity and uncertainty [5] [21]. By trusting another party, one reduces own concerns about a situation and establishes beliefs that a social interaction is handled fairly, responsibly, and with the absence of opportunistic behavior by all parties involved, without the presence of rules or customs [5] [22] [23]. In this context, the willingness to rely on another party is closely tied to own assessments of the other party's characteristics, especially with regard to integrity, benevolence, and competence [21] [24]. Trust is also strongly connected to perceived risk as both aspects have a strong impact on human behavior in social situations where uncertainty is present [7]. While trust serves as a catalyst of social exchange, risk represents a retardant, exposing a party to a perceived potential loss suffered by the actions of another party [7] [24].

Due to its key role in social interactions, trust remains a contemporary and widely researched topic. Especially when it comes to technology-enabled environments like the internet, researchers, e.g. from the IS field, have emphasized the importance to explore the trust concept more deeply in a variety of contexts [19] [21]. This applies particularly to the study of trust in new and unexplored IS contexts [20]. Of particular interest for present research is the existing body of IS literature around trust-based relationships between people and organizations as well as between people and technology [21]. In these investigations, for example, trust in ecommerce organizations unveiled as an important driver of online consumer behavior, trust in technology as a critical aspect in determining whether UCs use and rely on IS systems [5] [6] [21]. This may also be the case for blockchain technology and applications. Therefore, this research aims at contributing to the IS research discussion around trust between people and organizations respectively technology [21], exploring the trust aspect in the context of nascent blockchain technology and applications.

\subsection{Blockchain technology and trust}

In its generic form, the blockchain concept describes a distributed ledger that is maintained and governed autonomously in the digital space without any central authority [25]. The term blockchain stands for a distributed database that is shared within a peer-to-peer network and contains a sequence of interconnected blocks. These blocks comprise immutable, cryptographically secured, and tamper-free information around transactions that is verified via a de-centralized consensus mechanism within the distributed network [3]. Proposing this unique combination of characteristics, blockchain technology has attracted strong interest among academics and led researchers from different disciplines to explore features and commercial applicability of blockchain [1]. As well among practitioners, blockchain technology sparks high awareness, triggering a vast diversity of projects and initiatives across industries [26]. The financial sector is seen as pioneering the blockchain idea, having launched digital crypto-currencies as its most well-known application [27]. Other industries, such as businesses from the marketing field [28], as well explore approaches to leverage blockchain technology in order to develop new business models or to improve existing commercial applications. Therefore, blockchain frequently is referred to as the next big technological innovation that may reshape and disrupt the way UCs live and the way companies do business [29]. Though, while blockchain is surrounded by a lot of positive excitement, researchers also call for a differentiated discussion of the topic as the claimed disruption potential of blockchain may be exaggerated and as applications such as Bitcoin have several weaknesses, e.g. vulnerability to financial speculation [30].

The generation of trust is touted to be one of the central benefits offered by yet nascent blockchain applications. More so, blockchain technology is 
expected to take trust in the digital world to a new level that even the most reputable market players are not able to attain [1]. Therefore, some researchers even refer to blockchain as a solution able to facilitate the creation of trust-free systems, i.e. systems without trust concerns where transactions are guaranteed by the underlying technology [4]. Due to this critical role, various researchers already analyzed the trust aspect in the realm of blockchain technology and applications [3]. In this regard, the existing body of literature explored the role of trust in blockchain technology and applications predominantly from a technology-focused IS perspective that is closely related to engineering, programming, and computer science. This promoted an understanding of the role of trust that is strongly linked to technical design features of blockchain technology and applications, like trust created through peer verification of transactions or trust established via a tamper-proof blockchain architecture [3]. In contrast to that, present research aims at exploring the role of trust in blockchain technology and applications holistically from the perspective of the UC, expanding the existing body of knowledge in this area [14] [15]. Drawing upon extant IS literature [7], present research defines UC trust in blockchain technology and applications as the belief that allows UCs to willingly rely and become vulnerable to businesses offering blockchain applications after having assessed the application's characteristics. This definition unites the perspectives of IS trust research in settings between people and organizations, i.e. businesses offering blockchain applications, and between people and technology, i.e. blockchain applications and their underlying technology.

\subsection{The role of trust in technology adoption}

Information systems, such as e-commerce, online banking, or social media applications, are key tools in helping businesses enhance their competitive position in the marketplace and increase performance efficiency [31]. However, information technology can only unfold its full performance potential when being adopted and used [32]. In the process of technology adoption of digital applications facilitated via the internet, trust has been identified as one of the key drivers of acceptance.

In the area of e-commerce, there is evidence that trust represents an essential benefit and driver of ecommerce adoption [5] [6] [7]. Mechanisms that build trust are attributed the same importance as technical design features of e-commerce systems [5] [7]. Like this, technology adoption of e-commerce systems can be promoted by employing trust-building measures, such as strengthening beliefs that a vendor has no interest in cheating or offering a typical, user-friendly e-commerce web interface [5]. For e-commerce adoption, moreover, trust acts as an antecedent of usage behavior, by establishing confident expectations about the system, and as an antecedent of controllability, by reducing uncertainty [6]. When it comes to online banking, numerous research studies support the role of trust as a central aspect in technology acceptance [8] [9] [10]. More so, trust is attributed a multi-dimensional role in internet banking adoption, being strongly connected to three antecedents, namely perceived privacy, perceived security, and perceived trustworthiness [10]. In the area of social media and social networks, trust is found to have a positive influence on adoption of social platforms and systems [11] [12] [13]. Like this, trust is identified as a key determinant for UC usage of social network services while being strongly linked to the dimensions of perceived security and perceived privacy, two aspects that positively correlate with trust and, hence, technology acceptance [13]. Trust in social media applications can also be promoted by providing users with a high degree of control over their personal data [12], a prerequisite for sustained social network usage.

While trust is identified as a key driver in the technology adoption process of e-commerce, online banking, and social media applications, there is a need to explore whether the same applies also to blockchain technology and applications. Therefore, this research aims at unveiling new insights that may more holistically assess the role of trust in UC technology adoption of blockchain technology and applications.

\section{Research methodology}

The present research employs an inductive, theorybuilding process that uses case studies to create theoretical constructs from empirical evidence [33]. As opposed to a deductive, theory-testing approach, an inductive, theory-building research strategy is selected due to the novelty of the research topic. Research around trust in blockchain technology and applications from the UC angle is yet scarce. Hence, limited insights around this critical and, for practitioners, significant research case exist. Using an inductive, case-based approach facilitates the generation of theories in the nascent area of blockchain technology by being closely connected to data [33]. Additionally, the inductive approach permits combining data sets that originate from diverse methodologies and sources, offering the possibility to triangulate achieved results and, consequently, to conceptualize valid and robust theoretical constructs [34]. Therefore, the employed inductive research strategy serves as an avenue from the exploration of rich qualitative data towards future deductive, theory-testing research [35] in the field of blockchain technology. 


\subsection{Sample and data collection}

Present research uses a two-step qualitative approach [36] [37] to explore the role of trust in the acceptance process of blockchain technology and applications. The first research step consists of qualitative in-depth interviews [38] among experts who have extensive expertise in the area of blockchain technology and applications. Instead of actual UCs, experts in the field of blockchain technology were identified as an ideal source for the purpose of this research as blockchain applications are, due to their nascent nature, generally not yet available to the mainstream UC. Employing a theoretical sampling strategy [39], informants were recruited based on their capacity to illuminate and extend the knowledge around benefits of blockchain technology and applications from the perspective of the UC [35], whereas trust represented a key aspect within the investigation. With this sampling objective in mind, experts were selected based on their experience in the field of blockchain, occupation, educational background, and country of origin. In this context, particular emphasis was put on the aspect of blockchain experience, ensuring that all informants have extensive, well-proven knowledge of the topic. As far as origin, occupation, and education are concerned, the recruitment strategy pursued diversity to promote a richness of different perspectives. As shown in table 1, this approach resulted in a sample of 14 knowledgeable experts, with six working in blockchain start-up companies, three in larger corporations, two in academia, and three in the financial space related to digital currencies and other blockchain applications. By conducting interviews with at least two informants from four different occupation fields, the sample aspires to introduce diverse, relevant angles on the research while at the same time reproducing findings within each occupation group. This approach is commensurate with the established research strategy of building theories from case study research [33]. The sample size of 14 informants resulted in a saturation of conceptual insights [39] and is in line with the prevailing paradigm of sound qualitative research which allows the use of only few sources to obtain information-rich empirical data [34]. A concise, semi-structured interviewer guideline was used to provide structure and directive in the interviewing process, but also to allow for flexibility and leeway in the conversation with informants [40]. The guideline included the key research questions in an open-ended format and explored perceived benefits and barriers - including trust - of blockchain technology and applications from the UC perspective, but also definitions of blockchain terminology in UC language and other topics. In line with the prevailing strategy to design questions for deductive, qualitative research, questions were developed independently from existing studies and theories and focused on the key themes of investigation [40]. To explore benefits and barriers, the following questions were used: What does blockchain technology stand for? What are the benefits that blockchain technology promises to users/consumers? Why can users/consumers believe in these promised benefits? What are the weaknesses of blockchain technology? Why is it weak at these aspects?

All qualitative in-depth interviews were conducted in March/April 2018 primarily via video calls, in a few cases even in person. The interviews (average length: 43 minutes) were audiotaped with the permission of the informants and transcribed to ensure accuracy and completeness of the obtained empirical data.

Table 1: Informants of in-depth expert interviews (research step 1)

\begin{tabular}{|l|l|l|l|}
\hline Pseudonym & Demographics & Industry / occupation & Degree \\
\hline Luke & Australia (male/46) & Start-up - Loyalty industry / CEO \& Founder & Marketing, Economics, Psychology \\
\hline Tom & Germany (male/37) & Start-up - Media industry / COO & Event Management, Advertising \\
\hline DeAndre & South Africa (male/39) & Start-up - IT consulting / CEO \& Founder & Commerce of Information Systems \\
\hline Zhao & USA (male/32) & Start-up - IT development / CEO \& Founder & Computer Programming, Music \\
\hline Leo & India (male/43) & Start-up - Tech industry / Business Developer \& Operations & Computer Applications, Business \\
\hline Alex & Germany (male/44) & Start-up - Media industry / CEO \& Founder & Law \\
\hline Luiz & Brazil (male/39) & Corporation - IT industry / Researcher \& Software Developer & Computer Science \\
\hline Marc & France (male/55) & Corporation - Media / Researcher \& Security Thought Leader & Microelectronics, Engineering \\
\hline Jay & China (male/22) & Corporation - Tech industry / Researcher \& Software Engineer & Computer Science \\
\hline Bruce & Netherlands (male/35) & Academia - Computer Science / Researcher \& Lecturer & PhD, Computer Science \\
\hline Mitch & USA (male/52) & Academia - Supply Chain \& Ops / Researcher \& Lecturer & Industrial Systems Engineering, Business \\
\hline Kiara & Russia/USA (female/39) & Finance - Consulting \& Investment / Entrepreneur \& Consultant & PhD, Economics \\
\hline Sami & Spain/Germany (male/31) & Finance - Consulting / Investment Consultant & PhD, International Business Administration \\
\hline Jenny & China (female/36) & Finance - Investment / Director of Customer Relationship & Business Administration \\
\hline
\end{tabular}


Table 2: Informants of the qualitative survey (research step 2)

\begin{tabular}{|l|l|}
\hline Pseudonym & Demographics \\
\hline Matt & South Carolina (male/28) \\
\hline Emma & Georgia (female/28) \\
\hline Anant & Wisconsin (male/33) \\
\hline Jayden & Texas (male/24) \\
\hline José & Georgia (male/28) \\
\hline Scott & Texas (male/23) \\
\hline Greg & New York (male/28) \\
\hline Dee & Texas (female/33) \\
\hline Noah & New York (male/26) \\
\hline Jackson & South Dakota (male/40) \\
\hline Olivia & Texas (female/45) \\
\hline Min & Alabama (male/28) \\
\hline Juan & Washington (male/31) \\
\hline Braxton & California (male/18) \\
\hline Han & New York (male/26) \\
\hline Owen & California (male/49) \\
\hline Efren & New York (male/25) \\
\hline Sofia & New Jersey (female/31) \\
\hline Jim & California (male/38) \\
\hline & \\
\hline
\end{tabular}

In the second research step, additional, qualitative information was sourced among U.S.-based Bitcoin owners via a qualitative online survey [41]. The cryptocurrency Bitcoin [25] is one of the most widely used blockchain applications. Therefore, Bitcoin owners represent an excellent target group to conduct blockchain research among actual blockchain UCs. With the objective to triangulate the findings obtained in the qualitative in-depth interviews of the first step [42], this second research represents a fresh, independent source of insights on the research topic that may unveil new insights or confirm previous findings.

The questionnaire of the qualitative survey consisted of a short screener and a more extensive main questionnaire that included the same open-ended questions that had already been used in the in-depth interviews of the first research step. In this context, the wording of the questions was slightly adjusted for the online survey setting without changing the meaning. The use of open-ended questions in the main questionnaire, in contrast to closed-ended questions with pre-defined answer options, is commensurate with the employed inductive theory-building approach [33], promoting the unbiased discovery of insights relevant to the topic [38].

The qualitative survey employed common design techniques for online questionnaires, such as asking respondents to be very specific in their answers or providing large text boxes [43]. Applying a theoretical sampling strategy [39] that did not aim at sourcing a representative sample of U.S.-based Bitcoin owners, informants were required to have a good/very good knowledge of blockchain technology and applications, in addition to owning Bitcoin. The qualitative survey (average length: 12 minutes) was finally conducted in May 2018 via the Amazon MTurk platform. This resulted in a sample of 19 U.S.-based Bitcoin users visualized in table 2 - that lead to a saturation of conceptual insights [39] (79\% male, average age: 31 years old).

\subsection{Data analysis}

The empirical data of both research steps was analyzed using the qualitative data analysis software MAXQDA. For the analysis of the obtained free-form, textual data, a three-stage coding process originating from grounded theory was conducted [44] [45]. The employed case-based, theory-building research strategy draws upon the grounded theory analysis approach, allowing to unveil unique patterns of each informant's answers in a within-case investigation before generalizing insights across informants [33]. In the first stage, open coding was used to identify emerging codes and concepts in the data by performing a line-by-line text analysis of each informant's responses [46]. In line with the objectives of present research to build theory around trust and the benefits of blockchain technology and applications from the UC perspective, open coding facilitated the creation of informant-generated theoretical constructs [47]. Coding stage two performed focused coding to compare the emerging open codes across cases and to discover the most significant codes of stage one. The focused coding stage pursued to synthesize and capture higher-level categories existing within the empirical data [48]. In the third coding stage, theoretical coding was employed to combine the obtained codes and categories with the objective to integrate those into theory around the benefits of blockchain technology and applications from the UC angle [49].

\section{Results}

Both qualitative research steps produced rich empirical data. The majority of the obtained insights can be attributed to the area of UC knowledge and perceptions of, but also UC expectations towards blockchain technology and applications. Like this, the research generated extensive insights around perceived benefits of blockchain technology and applications from the UC angle. In this context, trust unveils as a critical benefit to the UC that may play a key role in the technology adoption process. 


\subsection{Benefits of blockchain technology and applications}

Generally, informants described a vast array of benefits that blockchain technology and applications can potentially offer to lead to adoption. These benefits can be categorized in two functional benefit dimensions, coded as economic and system-/ process-related benefits, and two emotional benefit dimensions, coded as social and personal benefits.

Functional benefits. Economic benefits of blockchain technology and applications deliver value to UCs by conserving and reinforcing UC resources in terms of time, money, and effort. More specifically, economic benefits refer to the promises of blockchain around saving costs and enhancing returns (cost savings), enabling easy and efficient processes (efficiency), and speeding up processes (speed). Most UC benefits can be described as system- and processrelated benefits and relate to functional aspects that are closely connected with technical design features of blockchain technology and applications [14]. Systemand process-related benefits deliver value to UCs by employing a new, enhanced approach to existing systems and processes and by offering novel solutions to problems. Like this, system- and process-related benefits refer to the promised characteristics of blockchain around providing an environment where UCs can remain anonymous (anonymity), enabling automated processes (automation), reliably encrypting information (cryptography), making worldwide processes easy to handle (global reach), being impossible to manipulate and change (immutability), documenting and storing information (registry), and making tracking and tracing easy (traceability).

Emotional benefits. Social benefits deliver value to UCs by letting them take part in the shared process and by making them feel stimulated and engaged as an official part of the cutting-edge, trailblazing blockchain movement. In particular, social benefits describe the fact that blockchain technology and applications let UCs participate in the shared systems of the community (participation) and incentivize UCs to proudly show that they are pioneers of the blockchain movement (pioneer role). The benefit of being in a pioneer role, however, will most likely disappear as blockchain technology and applications mature. Finally, personal benefits provide value to UCs by giving them the feeling to have control over processes they participate in and data they share in the community (control) as well as by making UCs identify themselves with the values of the blockchain movement (self-identification).

In addition to the benefits that can be clearly assigned to a single benefit dimension, a set of three benefits covers both functional and emotional aspects to the UC: these 'hybrid' UC benefits refer to blockchain's promise to function as a distributed system in absence of any intermediary agents (de-centrality), to guarantee secure and safe processes and handling of information (security), and to build a trustworthy and trustful environment (trust). The hybrid benefits of decentrality, security, and trust may be the most essential and critical benefits of blockchain technology and applications to the UC. As these three benefits represent both functional and emotional benefits, they are most likely to have the biggest impact with UCs [50], making them potential key drivers of adoption of any blockchain application. Table 3 provides an overview of the identified UC benefits of blockchain technology and applications.

\section{Table 3. UC benefits of blockchain technology and applications}

\begin{tabular}{|c|c|c|c|}
\hline Category & Sub-category & Emerging codes & \\
\hline \multirow[t]{2}{*}{$\begin{array}{l}\text { Functional } \\
\text { benefits }\end{array}$} & $\begin{array}{l}\text { Economic } \\
\text { benefits }\end{array}$ & $\begin{array}{l}\text { Cost savings } \\
\text { Efficiency } \\
\text { Speed }\end{array}$ & \multirow{4}{*}{$\begin{array}{l}\text { De-centrality } \\
\text { Security } \\
\text { Trust }\end{array}$} \\
\hline & $\begin{array}{l}\text { System- and } \\
\text { process-related } \\
\text { benefits }\end{array}$ & $\begin{array}{l}\text { Anonymity } \\
\text { Automation } \\
\text { Cryptography } \\
\text { Global reach } \\
\text { Immutability } \\
\text { Registry } \\
\text { Traceability }\end{array}$ & \\
\hline \multirow[t]{2}{*}{$\begin{array}{l}\text { Emotional } \\
\text { benefits }\end{array}$} & Social benefits & $\begin{array}{l}\text { Participation } \\
\text { Pioneer role }\end{array}$ & \\
\hline & $\begin{array}{l}\text { Personal } \\
\text { benefits }\end{array}$ & $\begin{array}{l}\text { Control } \\
\text { Self-identification }\end{array}$ & \\
\hline
\end{tabular}

\subsection{The role of trust in the context of blockchain technology and applications}

Together with the benefits of de-centrality and security, trust represents one of the key benefits of blockchain technology and applications that encompasses all four identified benefit dimensions, i.e. economic, system- and process-related, social, and personal benefits. Like this, the three hybrid benefits are strongly connected to each other: "In certain cases, users do not trust this centralized thing, so they would need a de-centralized solution, or blockchain... it's hard for users to trust each other, or trust a central entity." (Jay) "To me, blockchain stands for the principles of decentrality, security, and trust." (Sami) It represents " $a$ much more secure and trusted network." (Olivia) "Essentially, [blockchain is] a trust building machine." (Juan) "It implies a common and equal platform that builds trust among the users." (Jim) "Trust is a big topic 
and a true benefit. You can count on it that everything and everyone plays by the rules. Therefore, trust is, for me, the biggest benefit of blockchain, from which, more or less, all other benefits can be derived." (Alex)

Economic benefits. The trust established via blockchain technology and applications has the potential to create cost savings for UCs in business-toconsumer (B2C) contexts: "I had excellent experiences here in Brazil with Airbnb..., but I still depend on Airbnb... So when you start having the blockchain networks, individuals can transact directly without those companies, so it's better for the individuals because they don't have to share part of the profit... They can have lower cost. They can have better returns due to the trust that the blockchain network provides." (Luiz) The same applies to business-to-business (B2B) contexts where the trust generated by blockchain applications has the power to safe costs and improve returns for UCs: "The supply chain today is executed by an intermediary, shaking hands on both sides, to the left to the right, and then they take a cut out of both sides. If I don't need to do that, and if I can get those validations independently, within a system that stands for trust by itself, I now actually have streamlined my entire chain. This can have a huge financial implication." (Mitch) In addition to cost savings, trust is also an important aspect when it comes to speeding up processes and making processes more efficient: "Blockchain creates a highly trustworthy environment where you can more easily and quicker, and sometimes also cheaper transfer value and trade assets." (Kiara) "Of course, you do gain efficiencies. This is mainly because you are able to solve all of those dispute issues. Processes become more effective as I don't have to challenge and question anything. And this is all due to the trust aspect." (Alex)

System-and process-related benefits. Trust is a critical benefit of blockchain technology and applications that can also be regarded as a benefit that provides value to UCs by employing a new, more trustworthy approach to existing systems and processes and by offering novel solutions to problems that UCs can trust. This is mainly because trust is strongly tied to other system- and process- related benefits, either supporting them to unfold their full potential, in an antecedent role, or being strengthened by them as an outcome. Like this, trust is, for example, strongly connected to the benefits of immutability, anonymity and of being a registry as the immutable, sometimes anonymous records created by blockchain applications generate trust: "The fact that the data is immutable, meaning the majority... in the blockchain will trust the state of the record, is a benefit. So now I don't have to trust a central authority... because my record's immutable. I don't have to worry about some central authority changing." (Leo) As well, trust is closely tied to the benefit of automation. On one hand, trust is prerequisite for UC willingness to use an automated blockchain solution. On the other hand, trust will also be created by automated blockchain processes facilitated e.g. via smart contracts: “The automation of processes creates trust for all parties who participate in the blockchain process." (Tom) "I can do business with somebody in Kenya based on blockchain, and we can create a smart contract that says that the money would be in escrow until the actual transaction is completed, so now I can do peer-to-peer transaction with untrusted parties. So that's an unmet need that definitely exists today." (Leo) When it comes to the benefit of blockchain technology and applications to reliably encrypt information, trust comes into play as a major outcome: "Trust in the big finance corporations was shuttered by the financial crisis. Additionally, there are those data scandals coming up with Facebook and so on. I believe blockchain technology can re-establish trust through the underlying cryptography." (Sami) "As the promise of blockchain is that the data is decentralized, and strong cryptography is protecting it, it becomes virtually impossible to change any of the data, which adds a significant improvement in overall trust to the system." (Luke)

Social benefits. Within the shared, trustful process of the cutting-edge blockchain community, trust serves as a facilitator for UCs to participate in blockchain applications. Therefore, UCs feel engaged and secure by being part of the blockchain process that allows them to interact with unknown people in a secure way they can trust and rely on: "This shared [blockchain] data cannot be tampered with. You can share it with people that you don't necessarily trust but yet, at the same time, you can come to common agreement on what the data is and you have a very low risk of it being changed against the rules that you have currently agreed on. This gives you a good feeling." (Bruce)

Personal benefits. Blockchain technology and applications provide value to UCs by giving them the feeling they have control over processes they participate in and data they share in the community. Especially the feeling of being in control generates a trustful connection of UCs with blockchain applications. This may be an important aspect to promote technology adoption among UCs: "So giving people access to the data that is held about them and potentially even rewarding them for access to it or giving them control back over it, I think will go a long way towards building new types of trust with customers." (Luke)

Despite trust potentially being one of the key benefits of blockchain technology and applications, it may not yet fully live up to its promises. Trust in some blockchain applications was shuttered, showing weaknesses like unsecure blockchain systems, volatility 
in financial blockchain applications, a need for more knowledge on the UC side, or a lack of regulation: "You know what the problem is: you look at these exchanges that have been hacked and wallets that have been lost... I mean there is still some gaps... The fact that A) it just had a major crash $B$ ) people don't really know enough about it and C) it's not really regulatory monitored or managed, that's a big issue." (DeAndre) Also, it may be a major challenge to convince UCs to believe in the trustworthy, reliable environment generated by blockchain technology and applications: "Why would I trust more something where nobody controls anything and it's everybody who is controlling? Why should I trust more my neighbor than my bank?” (Marc) All these weaknesses may need to be addressed to foster UC acceptance of blockchain applications.

\section{Discussion and contribution}

Present research explores the role of trust in blockchain technology and applications from the UC perspective by centering an inductive, qualitative case study around two research questions.

Is trust a relevant benefit of blockchain technology and applications to the UC? Results show that trust is a highly relevant benefit that spans across both functional (economic and system-/ process-related) and emotional benefit (social and personal) dimensions. Therefore, trust may have an elevated impact with UCs and may be a critical aspect for adoption of blockchain technology and applications.

Are there different facets of trust that UCs perceive as relevant and beneficial when it comes to blockchain technology and applications? Exploratory findings unveil that trust is a multidimensional benefit that meets both functional and emotional UC needs. Moreover, our research shows that trust is a highly relevant aspect that serves as a facilitator to other benefits, like cost savings, efficiency, speed, automation, or participation, helping those benefits to unfold their full potential. As well, trust is strengthened by other benefits, e.g. cryptography, immutability, registry, traceability, or control, being a major outcome of these benefits. Hence, the generated insights facilitate a differentiated in-depth understanding of the role of trust for the UC.

Providing these answers to the formulated research questions, the theoretical contribution [18] of our work to the research field is twofold: First, our research takes a UC-centric perspective on benefits of blockchain technology and applications in general and trust in particular, creating conceptual and empirical insights that complement and expand existing research that predominantly has a technology-oriented focus. More specifically, present research integrates the benefits of blockchain technology and applications, including the trust aspect, within a novel, structured UC benefits framework that precisely identifies and describes the functional and emotional benefit dimensions relevant and critical to the UC. Second, this research conducts an in-depth exploration of the role of trust in blockchain technology and applications that unveils different meaning facets of trust existing from the UC perspective. By doing this, our research takes a scarcely researched perspective on the topic and identifies trust as a key benefit that may be critical for technology acceptance of blockchain technology and applications. This suggests that trust research provides a rich and useful conceptual foundation for the study of blockchain phenomena.

Findings of our research may help practitioners in the development of blockchain applications, providing directional guidance on how to best address the trust aspect in the design process in order to promote UC acceptance. For example, blockchain designers may be able to build UC trust in blockchain applications by ensuring that sensitive personal information is reliably encrypted and by providing evidence that the system allows UCs to maintain control over the data they share. As a consequence, the increased trust may incentivize UCs to try out and use a blockchain application. As the constructs created by our research, moreover, emerge from the employed theory-building process, they are, having undergone a repeated verification cycle, readily testable and measurable [33]. Therefore, the generated concepts are ready to be used by researchers in future investigations of blockchain technology and applications from the UC perspective, e.g. as elements in further qualitative or quantitative research. For example, quantitative research around economic UC benefits of blockchain applications may introduce trust as an important facilitator and measure how the trust aspect, when changing over time, impacts UC perceptions of benefits such as speed, cost savings, or efficiency. Additionally, the generated insights can guide blockchain practitioners for crafting compelling value propositions for blockchain applications that are backed by a trust definition and benefits relevant and critical to the UC. As value propositions provide guidelines for product marketing [51], the findings from this research can fuel the communications process with (potential) UCs by defining leitmotifs for trustworthy messaging and application positioning. Value propositions, moreover, guide the product development process [51]. Like this, the identified UC benefits and especially the different meaning facets identified for trust can direct the product design process of blockchain applications. These insights determine on which aspects to put most emphasis in the technical development 
process in order to have greatest impact with UCs and to promote adoption.

\section{Limitations and future research}

The results of our study may serve researchers for future blockchain-related work and guide practitioners in developing powerful blockchain applications that have a chance of UC acceptance, while application design is strongly linked to a differentiated understanding of trust that is relevant to the UC. Nonetheless, there are several limitations to this study, serving as gateways towards future blockchain research.

First, our research takes a very broad approach, exploring the trust aspect and the benefits of blockchain technology and applications independent from any specific application. These insights may not provide guidance tailored to specific use cases, such as identifying the most important UC benefits or investigating the role of trust in the acceptance of blockchain applications e.g. for tracking and tracing food. Therefore, future research around trust and UC benefits of blockchain technology and applications should focus on specific application cases in order to provide a deeper understanding around which benefits may best promote UC acceptance of particular applications.

As well, our research yet only derives insights from a qualitative, theory building process. Like this, only directional insights can be derived when it comes to the impact of certain benefits on the technology adoption process. Future research should therefore evaluate and quantify the contribution of each identified benefit for UC acceptance, using a quantitative research approach for the analysis of different blockchain applications. Such future quantitative research may help in determining to what extent trust and other benefits can drive UC adoption in different application settings.

\section{Conclusion}

Employing an inductive, theory-building process, present research sheds light on the scarcely explored topic of benefits offered by blockchain technology and applications to UCs, putting particular focus on the key benefit of trust. By shifting the research discussion from a predominantly technology-oriented design angle to a UC-centric perspective, present research reminds researchers and practitioners alike that for the acceptance and sustainable success of blockchain applications, it is critical to develop the underlying technology against the backdrop of UC needs, as it is those UCs that finally decide on the success or failure of any application.

\section{References}

[1] R. Beck, M. Avital, M. Rossi, and J. B. Thatcher, "Blockchain Technology in Business and Information Systems Research", Business \& Information Systems Engineering 59(1), 2017, pp. 381-384.

[2] B. Notheisen, J. B. Cholewa, and A. P. Shanmugam, "Trading Real-World Assets on Blockchain", Business \& Information Systems Engineering 59(1), 2017, pp. 425-440.

[3] S. Seebacher and R. Schüritz, "Blockchain Technology as an Enabler of Service Systems: A Structured Literature Review," in Exploring Services Science: 8th International Conference, IESS 2017, Rome, Italy, Proceedings, S. Za, M. Drăgoicea, and M. Cavallari, Eds. Springer International Publishing, Cham, Germany, 2017, pp. 12-23.

[4] R. Beck, J. Stenum Czepluch, N. Lollike, and S. Malone, "Blockchain - The Gateway to trust-free cryptographic transactions”, Research Papers 153, 2016.

[5] D. Gefen, E. Karahanna, and D. W. Straub, "Trust and TAM in Online Shopping”, MIS Quarterly 27(1), 2003, pp. 51-90.

[6] P. A. Pavlou and M. Fygenson, "Understanding and Predicting Electronic Commerce Adoption”, MIS Quarterly 30(1), 2006, pp. 115-143.

[7] P. A. Pavlou, "Consumer acceptance of electronic commerce”, International Journal of Electronic Commerce 7(1), 2003, p. 101-134.

[8] S. Dimitriadis and N. Kyrezis, "The effect of trust, channel technology, and transaction type on the adoption of selfservice bank channels”, The Service Industries Journal 31(8), 2011, pp. 1293-1310.

[9] E. L. Slade, Y. K. Dwivedi, N. C. Piercy, and M. D. Williams, "Modeling Consumers' Adoption Intentions of Remote Mobile Payments in the United Kingdom”, Psychology \& Marketing 32(8), 2015, pp. 860-873.

[10] S. Yousafzai, J. Pallister, and G. Foxall, "Multidimensional role of trust in Internet banking adoption”, The Service Industries Journal 29(5), 2009, pp. 591-605.

[11] M. Hajli, “A research framework for social commerce adoption”, Information Management \& Computer Security 21(3), 2013, pp. 144-154.

[12] M. Ng, "Factors influencing the consumer adoption of Facebook”, Computers in Human Behavior 54, 2016, pp. 491500.

[13] D.-H. Shin, “The effects of trust, security and privacy in social networking”, Interacting with Computers 22(5), 2010, pp. 428-438.

[14] M. Risius and K. Spohrer, "A Blockchain Research Framework”, Business \& Information Systems Engineering 59(6), 2017, pp. 385-409.

[15] J. Lindman, M. Rossi, and V. K. Tuunainen, "Opportunities and risks of Blockchain Technologies in payments - a research agenda”, in Proceedings of the 50th Hawaii International Conference on System Sciences, Waikoloa Village, HI, USA, 2017, pp. 1533-1542.

[16] J. A. Burrows, “Does Blockchain Generate Trust?”, 2018. [Online]. Available: https://medium.com/@adaburrows/does- 
blockchain-generate-trust-5e96148ae597. [Accessed 4 June 2018].

[17] J. Woods, “Blockchain: Securing Trust \& Identity”, 2018. [Online]. Available: https://medium.com/crypto-oracle/ blockchain-securing-trust-identity-20eb0f05eead. [Accessed 30 May 2018].

[18] S. Gregor, "The Nature of Theory in Information Systems”, MIS Quarterly 30(3), 2006, pp. 611-642.

[19] I. Benbasat, D. Gefen, and P.A. Pavlou, "Introduction to the Special Issue on Novel Perspectives on Trust in Information Systems”, MIS Quarterly 34(2), 2010, pp. 367371.

[20] I. Benbasat, D. Gefen, and P. A. Pavlou, “Call for Papers: Special Issue on Novel Perspectives of Trust in Information Systems," MIS Quarterly 32(2), 2008, pp. 465-466.

[21] M. Söllner, I. Benbasat, D. Gefen, J. M. Leimeister, and P. A. Pavlou, "Trust”, in MIS Quarterly Research Curations, A. Bush and A. Rai, Eds., 2016, pp. 1-9.

[22] N. Luhmann, Trust and power, Wiley, New York, NY, USA, 1979.

[23] R. C. Mayer, J. H. Davis, and F. D. Schoorman, “An integrative model of organizational trust" Acad. Management Rev 20(3), 1995, pp. 709-734.

[24] D. Gefen and P. A. Pavlou, "The Boundaries of Trust and Risk”, Information Systems Research 23(3), 2012, pp. 940 959.

[25] S. Nakamoto, "Bitcoin: a peer-to-peer electronic cash system”, 2008. [Online]. Available: https://bitcoin.org/

bitcoin.pdf. [Accessed 27 January 2018].

[26] B. Marr, "35 Amazing Real World Examples Of How Blockchain Is Changing Our World”, 2018. [Online]. Available: https://www.forbes.com/sites/bernardmarr/2018/ 01/22/35-amazing-real-world-examples-of-how-blockchainis-changing-our-world/\#47ef709e43b5. [Accessed 23 January 2018].

[27] P. Vigna and M. Casey, The age of cryptocurrency: How bitcoin and digital money are challenging the global economic order, St. Martin's Press, New York, NY, USA, 2015.

[28] D. Newman, "4 Ways Blockchain Will Transform Digital Marketing And Advertising”, 2017. [Online]. Available: https://www.forbes.com/sites/danielnewman/2017/11/14/4ways-blockchain-will-transform-digital-marketing-andadvertising/\#45045c573fb7. [Accessed 23 January 2018].

[29] F. Schebesta, "How Blockchain Is Disrupting Digital Marketing”, 2017. [Online]. Available: https://www.

singlegrain.com/digital-marketing/how-blockchain-isdisrupting-digital-marketing/. [Accessed 23 January 2018].

[30] M. Avital, R. Beck, J. L. King, M. Rossi, and R. Teigland, "Jumping on the Blockchain Bandwagon: Lessons of the Past and Outlook to the Future", in Proceedings of the 37th International Conference on Information Systems, Dublin, Ireland, 2016, pp. 1-6.

[31] J. Bradley, "If We Build It They Will Come? The Technology Acceptance Model”, in Information systems theory: Explaining and predicting our digital society 1, Y. Dwivedi, M. R. Wade, and S. L. Schneberger, Eds., Springer, New York, NY, USA, 2012, pp. 19-36.
[32] F. D. Davis, R. P. Bagozzi, and P. R. Warshaw, "User Acceptance of Computer Technology”, Management Science 35(8), 1989, pp. 982-1003.

[33] K. M. Eisenhardt, "Building Theories from Case Study Research” The Academy of Management Review 14(4), 1989, pp. 532-550.

[34] M. Q. Patton, Qualitative research \& evaluation methods: Integrating theory and practice, Sage, Los Angeles, CA, USA, 2015.

[35] K. M. Eisenhardt and M. E. Graebner, “Theory Building from Cases: Opportunities and Challenges”, Academy of Management Journal 50(1), 2007, pp. 25-32.

[36] S. Sarker, X. Xiao, and T. Beaulieu, "Qualitative Studies in Information Systems: A Critical Review and Some Guiding Principles”, MIS Quarterly 37(4), 2013, pp. iii-xviii.

[37] M. Myers and D. Avison, Qualitative Research in Information Systems, Sage, London, UK, 2002.

[38] U. Flick, An introduction to qualitative research, Sage, Los Angeles, CA, USA, 2014.

[39] D. F. Birks, W. Fernandez, N. Levina, and S. Nasirin, "Grounded theory method in information systems research", European Journal of Information Systems 22(1), 2013, pp. 18.

[40] W. J. Gibson and A. Brown, Working with Qualitative Data, Sage, London, UK, 2009.

[41] H. Jansen, "The logic of qualitative survey research and its position in the field of social research methods", Forum: Qualitative Social Research 11(2), 2010. [Online]. Available: http://nbn-resolving.de/urn:nbn:de:0114-fqs1002110.

[Accessed 29 March 2018].

[42] E. P. Jack and A. S. Raturi, "Lessons learned from methodological triangulation in management research", Management Research News 29(6), 2006, pp. 345-357.

[43] J. D. Smyth, D. A. Dillman, L. M. Christian, and M. McBride, "Open-Ended Questions in Web Surveys", Public Opinion Quarterly 73(2), 2009, pp. 325-337.

[44] B. G. Glaser and A. L. Strauss, The discovery of grounded theory, Aldine de Gruyter New York, NY, USA, 1967.

[45] M. Wiesche, M. C. Jurisch, P. W. Yetton, and H. Krcmar, "Grounded Theory Methodology in Information Systems Research”, MIS Quarterly 41(3), 2017, pp. 685-701.

[46] J. M. Corbin and A. L. Strauss, Basics of qualitative research, Sage, Los Angeles, CA, USA, 2008.

[47] E. Blair, "A reflexive exploration of two qualitative data coding techniques”, Journal of Methods and Measurement in the Social Sciences 6(1), 2015, pp. 14-29.

[48] R. Thornberg and K. Charmaz, "Grounded Theory and Theoretical Coding", in The SAGE handbook of qualitative data analysis, U. Flick, Ed., Sage, London, UK, 2014, pp. 153169.

[49] J. A. Holton, “The Coding Process and Its Challenges”, in The SAGE handbook of grounded theory, A. Bryant and K. Charmaz, Eds., Sage, Los Angeles, USA, 2011, pp. 265-289.

[50] C. W. Park, D. J. MacInnis, and A. B. Eisingerich, Brand Admiration: Building A Business People Love, Wiley, Hoboken, NJ, USA, 2016.

[51] H. Thota and Z. Munir, Key concepts in innovation, Palgrave Macmillan, Basingstoke, UK, 2011. 